\title{
ARBUSCULAR MYCORRHIZAL SYMBIOSIS ALLEVIATES DROUGHT STRESS IMPOSED ON WHEAT PLANTS (TRITICUM AESTIVUM L.)
}

\author{
Metwally, A. $.^{1,2^{*}}-$ AzOOZ, M. $^{3}-\mathrm{NAFADY}, \mathrm{N}^{2}{ }^{2}-$ El-ENANY, A. ${ }^{2,4}$

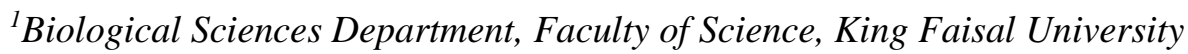 \\ Hofuf 31982, Saudi Arabia \\ ${ }^{2}$ Botany and Microbiology Department, Faculty of Science, Assiut University \\ Assiut 71516, Egypt \\ ${ }^{3}$ Botany Department, Faculty of Science, South Valley University, Qena 83523, Egypt \\ ${ }^{4}$ Biological Sciences Department, Sajer Faculty of Science and Arts, Shaqra University, Saudi \\ Arabia \\ ${ }^{*}$ Corresponding author \\ e-mail: ametwally@kfu.edu.sa \\ (Received 25 $5^{\text {th }}$ Apr 2019; accepted $15^{\text {th }}$ Nov 2019)
}

\begin{abstract}
Absract. The aim of this study was to determine the contribution of native arbuscular mycorrhizal fungi (AMF) inoculation to growth, pigmentation and grain yield of wheat plants (Triticum aestivum L.) grown under different levels of water deficiency [D0, 100\% Field Capacity (FC); D1, 75\% FC; D2, 50\% FC and $\mathrm{D} 3,25 \% \mathrm{FC}$. The results suggested that AMF inoculation has a beneficial effect on plant drought tolerance and effectively improved biomass and crop productivity of wheat plants grown under drought. Mycorrhizal symbiosis alleviates the inhibitory effect of drought stress via improving water status and chlorophyll biosynthesis of wheat plants. Mycorrhizal colonization increased gradually and was higher at the maturity stage under a low level of drought (D1). The mycorrhizal wheat plants had higher shoot phosphorous than non-mycorrhizal plants at all samplings regardless of levels of drought stress. In general, with all treatments, the content of photosynthetic pigment fractions was inhibited as the level of drought increased in the soil pot experiment. However, the photosynthetic pigment contents of mycorrhizal wheat plant leaves were significantly $(p<0.05)$ greater than those of non-mycorrhizal ones. The study/ concluded that the native mycorrhizae alleviate the drought stress by enhancement of the process of phosphorus uptake, pigment biosynthesis and accumulation of plant metabolites and may be used as a biofertilizer.
\end{abstract}

Keywords: arbuscular mycorrhizal, drought stress, biofertilizer, phosphorus, wheat

\section{Introduction}

Water shortage is considered one of the most significant environmental factors that affect plant growth and limit plant development and productivity in many arid and semiarid regions of the world. Also, seasonal water deficiency sometimes occurs in non-arid regions. Drought has a sharp decline in crop productivity, although many of these crops have many improved characteristics to withstand water shortage conditions (Bohnert et al., 1995; Zhu et al., 2012). Water deficit negatively influences the growth and metabolism of many plants, the response of plants differs depending on plant genotype, developmental stage, severity and duration of the stress (El-Enany et al., 2013, 2014).

Soil microorganisms are a very important component in the plant/soil system (Abd-Alla et al., 2014a,b; Kannenberg and Phillips, 2017). Symbionts can improve plant resistant to abiotic stresses by enhancing both plant nutrition and protection against the oxidative damage produced by the water deficiency (Ruíz-Lozano, 2003) and heavy metals (Rivera- 
Becerril et al., 2005). The symbiotic relation between arbuscular mycorrhizal fungi (AMF) and most plants provides nutrients, stimulates plant growth and increases the tolerance of plants against the stress (Barea et al., 2005; Abdel Latif and Chaoxing, 2014; Kyriazopouls et al., 2014; Shinde and Thakur, 2015). Arbuscular mycorrhizal fungi (AMF) can form mutualistic symbiotic associations with the roots of $80 \%$ of all terrestrial plant species (Smith and Read, 2008; Patale and Shinde, 2014). The AM symbiosis induced a higher improvement of physiological parameters in drought-sensitive plants than in droughttolerant plants and drought-sensitive plants obtained higher physiological benefit from the AM symbiosis (Quiroga et al., 2017). Plants grown under water deficiency have a lower stomatal conductance in order to conserve water. Previous studies have indicated that drought stress severely affects plant growth through various mechanisms, such as reduced leaf water potential, reduced rate of cell division, and altered plant water and nutrient relationships. Consequently, $\mathrm{CO}_{2}$ fixation is inhibited and photosynthetic rate reduced, resulting in less assimilate production for growth and yield of plants (Celebi et al., 2010; Farooq et al., 2012; Shinde and Singh, 2017).

There is considerable evidence suggesting that AMF has the potential to increase the tolerance of their host plants to water deficit stress (Asrar et al., 2012; Lazcano et al., 2014; Xiao-Qing et al., 2017). Studies have shown that the extraradical mycelia of AM fungi transfer water to their host plants under low soil moisture conditions and the AM fungi improve plant growth, development and yield (Augé et al., 2007), enhanced nutrient uptake (Michalis et al., 2013), an increase in the root hydraulic conductance (Bárzana et al., 2012), alterations in the soil's water retention properties (Augé, 2001), or improved osmotic adjustment (Aroca et al., 2007) and antioxidant activity (Bompadre et al., 2014). The beneficial functions of AMF may be of great importance to climate change, particularly with respect to water shortage and to the revegetation of degraded ecosystems; including coal mine spoil banks (Khalvati et al., 2010).

Wheat (Triticum aestivum L.) is the major food crop plants, are known to be commonly associated with AM fungi, which inhabit in agricultural soils contributing physiologically and ecologically to the health of both plants and soils (Li et al., 2012). Colonization of roots by AM fungi has been shown to increase the drought resistance of wheat (Al-Karaki and Clark, 1998). Therefore, our aim in the present study was to evaluate the potential of native species of AMF to mitigate the adverse effects of drought stress on wheat growth and for improved grain yield.

\section{Material and Methods}

\section{Production of mycorrhizal inoculum}

Native adapted AM fungi were isolated from the arid environment [Al-Uqair coast, AlAhsa, Saudi Arabia, (25³9'35.8'N 50'11'25.6”E)] and propagated for inoculums production. The most abundant mycorrhizal species selected and morphologically identified according to Schüessler and Walker (2010). Native AM fungi were propagated on maize (Zea mays. L) as host plant on the sterilized clay-sand mixture (50\% soil and 50\% sand). Plants were cultured in the greenhouse for 3 months. The roots colonized by AM fungi were checked during the culture, and the presence of spores was confirmed by sieving. One hundred grams of soil containing a mixture of mycorrhizal spores, extra-radical hyphae, and roots fragments applied as mixture culture inoculum. Non-mycorrhizal maize roots and sterilized soil used for the control treatment. 


\section{Experimental design and growth conditions}

Wheat grains (Triticum aestivum L.) were surface sterilized and grown in plastic pots filled with $4 \mathrm{~kg}$ sterilized soil at different levels of drought (D0, 100\% FC-D1, 75\% FC-D2, 50\% FC and D3, 25\% FC). The seedlings were thinned to 10 plants one week after germination. All pots were fertilized with $50 \mathrm{mg} \mathrm{N}-\mathrm{KNO}_{3} \mathrm{~g}^{-1}$ soil. Solutions of $\mathrm{K}_{2} \mathrm{HPO}_{4}$ were prepared and $\mathrm{P}$ was added at $30 \mathrm{or}^{2} \mathrm{mg}^{-1} \mathrm{~g}$ soil. A control treatment was also included. The experiment in a completely randomized design was performed by fifty- gram inoculum of AMF mixture and placed in pots below the grain of the tested plant (approximately contain 90-100 spores/10 g soil). Pots of the control treatments received the same volume of autoclaved inoculums. All pots contain 10 seedlings were kept in the greenhouse with day and night temperatures of 27 and $15^{\circ} \mathrm{C}$, respectively, day and night relative humidity of 70 and $80 \%$, respectively, and a photoperiod of $14 \mathrm{~h}$. Each treatment was replicated three times.

\section{Growth parameters and grain yield}

After 42 days of planting, some wheat plants were removed gently from the pots, washed with water. Then, plants were separated into shoots and roots and part of fresh roots and shoots were immediately frozen for analysis. The dry weights of the plants were recorded by placed the samples in an oven at $80^{\circ} \mathrm{C}$ until the dry weight was constant. At maturity, yield components [spike length, the number of grains per spike, grain yield per plant and 100- grain weight (seed index)] were determined on 3 plants for each treatment. Also, days to flowering and days to maturity were recorded for all treatments.

\section{Estimation of mycorrhizal colonization}

Root segments were separated from the plant, washed and then cut into one centimeter long pieces. The segments were cleared with $10 \%(\mathrm{w} / \mathrm{v}) \mathrm{KOH}$ at $70^{\circ} \mathrm{C}$ for 20 min and stained with $0.5 \%(\mathrm{w} / \mathrm{v})$ Trypan blue. The stain was prepared by mixing water, glycerin and lactic acid in proportions 1:1:1 (v/v/v). Mycorrhizal colonization was assessed by the method of Brundrett et al. (1984). Frequency of mycorrhizas (F\%), the intensity of mycorrhizal colonization in the root (M\%), and arbuscule frequency in roots (A\%) was calculated according to Trouvelot et al. (1986) using the MYCOCALC (http://www.dijon. inra.fr/mychintec/Mycocalc-prg/download.html) program.

\section{Quantification of phosphoros mycorrhizal dependency}

According to Plenchette et al. (1983), the dependency of mycorrhizal plants growth and Phosphorous $(\mathrm{P})$ uptake were calculated as:

$$
\frac{[\mathrm{P} \text { content }(\mathrm{M})-\mathrm{P} \text { content }(\mathrm{NM})]}{\mathrm{P} \text { content }(\mathrm{M})} \times 100
$$

where M, mycorrhizal plants and NM, non-mycorrhizal plants.

The concentration of $\mathrm{P}$ in the shoot was determined after digestion in a mixture of concentrated nitric and perchloric acids (4:1). Each sample was placed in $50 \mathrm{~mL}$ measuring flasks and $10 \mathrm{~mL}$ of the acid mixture was added. The mixture was first heated on fry pans to $90^{\circ} \mathrm{C}$ for $30 \mathrm{~min}$, and then temperature increased to $140^{\circ} \mathrm{C}$ to remove excess nitric acid. De-ionized water was added to make up to definite volume of 
the primary extract. An aliquot of this primary extract was diluted for determining phosphorus shoot concentration spectrophotometrically (Olsen and Sommers, 1982).

\section{Determination of photosynthetic pigments}

The fractions of pigments (chlorophyll a, chlorophyll $\mathrm{b}$ and carotenoids) were estimated using the spectrophotometric method recommended by Lichtenthaler (1987). The photosynthetic pigments were extracted from a definite weight of fresh leaf samples in $5 \mathrm{ml}$ of $95 \%$ ethyl alcohol at $60^{\circ} \mathrm{C}$, until colorless. Then the total volume was completed to $10 \mathrm{ml}$ with $95 \%$ ethyl alcohol and absorbance readings were followed with a spectrophotometer (Unico UV-2100 spectrophotometer. The extinction was measured against a blank of pure 95\% ethyl alcohol at three wavelengths of 452, 644 and $663 \mathrm{~nm}$. The concentration of chlorophylls and carotenoids were calculated as mg/g FW using the following equations:

$$
\begin{aligned}
& \text { Chlorophyll } \mathrm{a}=\left(13.36 \times \mathrm{A}_{663}\right)-\left(0.918 \times \mathrm{A}_{644}\right) \\
& \text { Chlorophyll } \mathrm{b}=\left(27.49 \times \mathrm{A}_{664}\right)-\left(3.87 \times \mathrm{A}_{663}\right)
\end{aligned}
$$

$$
\text { Carotenoids }=\left(4.2 \times \mathrm{A}_{452}\right)-[(0.0264 \times \text { Chl.a })+(0.46 \times \text { Chl.b })]
$$

\section{Statistical analysis}

The data were subjected to one-way ANOVA using the SPSS 10.0 software program. Means and standard errors were calculated for 3 replicate values. Means were compared by Duncan's multiple range test and statistical significance was determined at a $5 \%$ level.

\section{Results}

A total number of 7 morphotypes of native species of AMF were recovered from rhizosphere plants grown in a harsh environment. Based on the number of spores the seven species in stressed soils were Acaulospora sp., A. bireticulata (Rothwell \& Trappe), A. capsicula Blaszk., Glomusaggregatum Schenck and Smith, G. clarum Nicolson \& Schenck, G. geosporum (Nicol. \& Gerd.) Walkerand G. mosseae (Nicol. \& Gerd.) Gerd. \& Trappe. The most common native species (Acaulospora capsicula,Glomus aggregatum, and Glomus geosporum) were propagated and used as mixture inoculum for further experiments.

The experiment was conducted on Triticum aesativum L. under different levels of drought (D0, D1, D2, and D3) and inoculated with or without a mixture of native AM fungi to grow for 3 months. Under well-watered conditions, mycorrhizal inoculation significantly increased all the growth parameters. The fresh and dry weights of mycorrhizal plants increased significantly than non-mycorrhizal plants. The drought treatments significantly reduced the growth criteria of both the mycorrhizal and nonmycorrhizal plants (Table 1). The data indicated that drought treatments were significantly $(\mathrm{p}>0.05)$ reduced fresh or dry weights of wheat plant roots especially at the highest levels of drought (D2 and D3) as compared by reference control (D0). Inoculation of wheat plants with AM fungi stimulated the growth, especially the plants under drought. The data presented in Table 1 shows that all water deficit levels exerted an inhibitory effect on the root and shoot dry yield of non-mycorrhizal wheat plants. On 
the other side, the fresh and dry shoot weights of mycorrhizal plants showed an increase at all drought levels as compared with control plants.

Analysis of the data revealed that drought significantly affected days to flowering of wheat plants of which delayed as compared with control. Days to the flowering of mycorrhizal wheat plants grown under drought stress were significantly early flowering than those of their respective non-mycorrhizal counterparts. The period of maturity of wheat spike plants showed the effectiveness of mycorrhizal inoculation as shown in Table 2.

Table 1. Growth parameters of wheat plants in response to mycorrhizal inoculation grown under different levels (D0, D1, D2, and D3) of drought stress

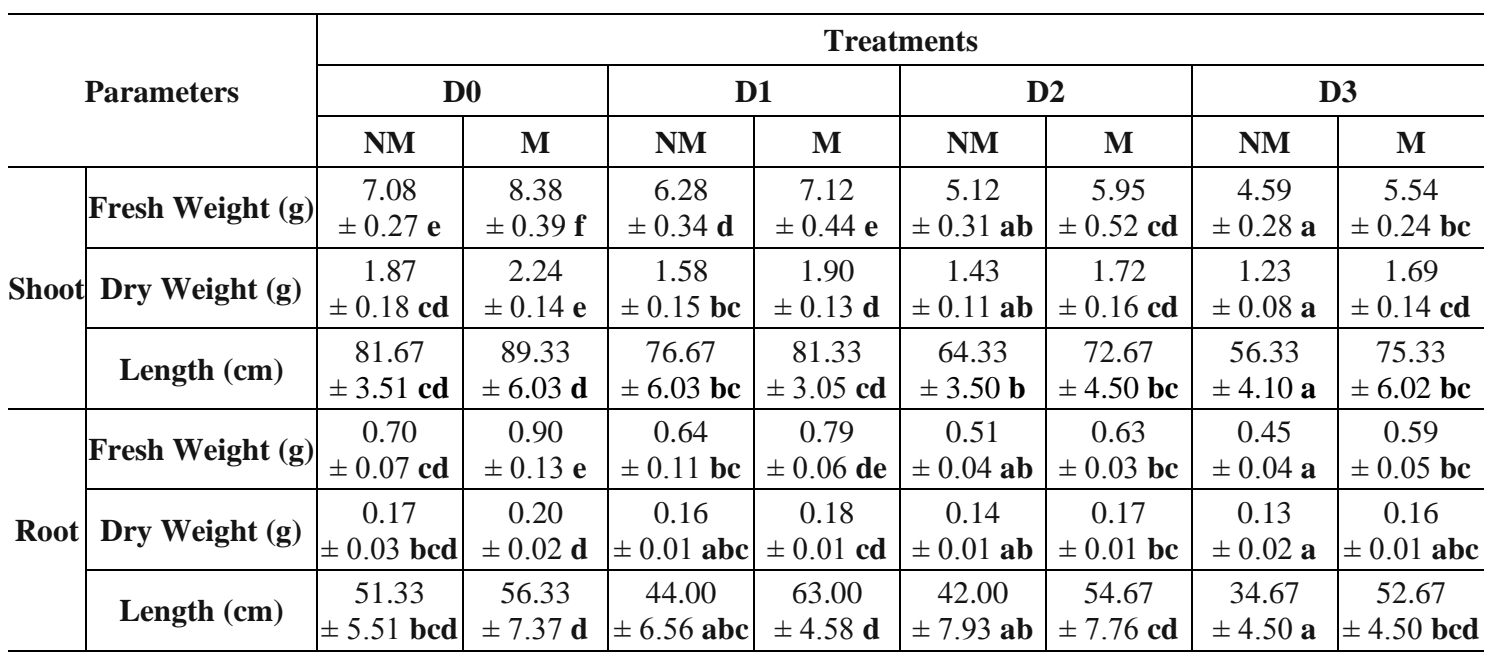

*NM nonmycorrhizal wheat plants; M, mycorrhizal wheat plants. Means in each column followed by the same letter are not significantly different $(\mathrm{P}<0.05)$ as determined by Duncan's test. Values are the means of three replications

Table 2. Yield components of wheat plants in response to mycorrhizal inoculation grown under different levels (DO,D1,D2, and D3) of drought stress

\begin{tabular}{|c|c|c|c|c|c|c|c|c|}
\hline \multirow{3}{*}{ Parameters } & \multicolumn{8}{|c|}{ Treatments } \\
\hline & \multicolumn{2}{|c|}{ D0 } & \multicolumn{2}{|c|}{ D1 } & \multicolumn{2}{|c|}{ D2 } & \multicolumn{2}{|c|}{ D3 } \\
\hline & NM & $\mathbf{M}$ & NM & $\mathbf{M}$ & NM & $\mathbf{M}$ & NM & $\mathbf{M}$ \\
\hline Days to Flowering & $\begin{array}{c}96.67 \\
\pm 1.52 \mathbf{b}\end{array}$ & $\begin{array}{c}86.33 \\
\pm 3.06 \mathbf{a}\end{array}$ & $\begin{array}{c}95.67 \\
\pm 3.06 \mathbf{b}\end{array}$ & $\begin{array}{c}88.00 \\
\pm 2.00 \mathbf{a}\end{array}$ & $\begin{array}{c}101.67 \\
\pm 1.53 \mathbf{a b} \\
\end{array}$ & $\begin{array}{c}89.00 \\
\pm 2.65 \mathrm{a}\end{array}$ & $\begin{array}{l}104.33 \\
\pm 1.15 \mathrm{c}\end{array}$ & $\begin{array}{c}94.33 \\
\pm 3.15 \mathbf{b}\end{array}$ \\
\hline Days to Maturity & $\begin{array}{l}130.33 \\
\pm 2.52 \mathbf{c} \\
\end{array}$ & $\begin{array}{l}121.67 \\
\pm 1.53 \mathrm{a} \\
\end{array}$ & $\begin{array}{r}131.00 \\
\pm 3.61 \mathbf{c} \\
\end{array}$ & $\begin{aligned} & 124.67 \\
& \pm 1.53 \mathbf{a b} \\
&\end{aligned}$ & $\begin{array}{l}135.67 \\
\pm 1.32 \mathbf{d} \\
\end{array}$ & $\begin{array}{r}127.33 \\
\pm 2.08 \text { bc } \\
\end{array}$ & $\begin{array}{r}138.00 \\
\pm 2.65 \mathbf{~ d a} \\
\end{array}$ & $\begin{array}{r}128.33 \\
\pm 1.45 \mathbf{b c} \\
\end{array}$ \\
\hline Spike Length (cm) & $\begin{aligned} & 8.67 \\
& \pm 0.32 \mathbf{c d} \\
&\end{aligned}$ & 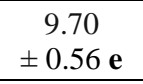 & 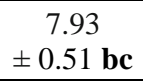 & $\begin{aligned} & 9.37 \\
& \pm 0.15 \mathrm{de} \\
&\end{aligned}$ & $\begin{array}{c}7.43 \\
\pm 0.71 \mathbf{a b} \\
\end{array}$ & $\begin{array}{c}8.93 \\
\pm 0.25 \mathrm{de} \\
\end{array}$ & $\begin{array}{ll} & 6.77 \\
\pm & 0.40 \mathbf{a} \\
\end{array}$ & $\begin{aligned} & 8.10 \\
& \pm 0.20 \mathbf{b c} \\
&\end{aligned}$ \\
\hline $\begin{array}{c}\text { Number of } \\
\text { Grains/Spike }\end{array}$ & $\begin{aligned} & 42.67 \\
& \pm 4.51 \mathrm{de} \\
&\end{aligned}$ & $\begin{aligned} & 48.6 \\
\pm & 4.21 \mathrm{e}\end{aligned}$ & $\begin{aligned} & 35.00 \\
& \pm 3.71 \mathbf{b c} \\
&\end{aligned}$ & $\begin{aligned} & 38.00 \\
& \pm 3.78 \text { cd } \\
&\end{aligned}$ & $\begin{aligned} & 29.00 \\
\pm & 2.52 \mathbf{a b}\end{aligned}$ & 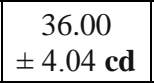 & $\begin{array}{c}24.67 \\
\pm 2.00 \mathbf{a}\end{array}$ & $\begin{aligned} & 33.33 \\
\pm & 1.53 \mathbf{b c}\end{aligned}$ \\
\hline $\begin{array}{c}\text { Grain Yield /Plant } \\
\text { (g) }\end{array}$ & $\begin{array}{c}14.27 \\
\pm 2.25 \mathbf{e}\end{array}$ & $\begin{array}{c}16.99 \\
\pm 0.29 \mathbf{f}\end{array}$ & $\begin{aligned} & 13.88 \\
\pm & 0.30 \mathrm{de}\end{aligned}$ & $\begin{array}{c}14.47 \\
\pm 0.49 \mathbf{e}\end{array}$ & $\begin{array}{c}12.12 \\
\pm 0.47 \mathbf{b}\end{array}$ & $\begin{aligned} & 13.19 \\
\pm & 0.69 \text { cd }\end{aligned}$ & $\begin{array}{c}11.12 \\
\pm 0.33 \mathbf{a}\end{array}$ & $\begin{aligned} & 12.38 \\
\pm & 0.24 \mathbf{b c}\end{aligned}$ \\
\hline $\begin{array}{c}\text { Seed Index } \\
(100 \text { grain weight in } \\
\text { g) }\end{array}$ & $\begin{aligned} & 31.75 \\
\pm & 0.27 \mathbf{c d}\end{aligned}$ & $\begin{aligned} & 37.18 \\
\pm & 1.15 \text { bc }\end{aligned}$ & $\begin{array}{l}30.15 \\
\pm 1.22 \mathbf{d}\end{array}$ & $\begin{aligned} & 32.02 \\
\pm & 2.13 \mathbf{c d}\end{aligned}$ & $\begin{aligned} & 26.87 \\
\pm & 2.90 \mathbf{b}\end{aligned}$ & $\begin{array}{c}30.42 \\
\pm 1.37 \text { bcd }\end{array}$ & $\begin{array}{c}21.72 \\
\pm 1.82 \mathbf{a}\end{array}$ & $\begin{array}{c}27.31 \\
\pm 2.01 \mathbf{b}\end{array}$ \\
\hline
\end{tabular}

*NM nonmycorrhizal wheat plants; M, mycorrhizal wheat plants. Means in each column followed by the same letter are not significantly different $(\mathrm{P}<0.05)$ as determined by Duncan's test. Values are the means of three replications 
The data showed that amongst all the treatments, days to maturity significantly $(\mathrm{P}<0.05)$ delayed under drought stress. Yield and its component consider the main target for the activity of plants. So the data recorded in Table 2 show that wheat plants inoculated with AMF caused a marked effect on the seed yield per plant and its components (spike length, grains of a spike, grains per plants and grains index, the weight of 100 seeds) in comparison to the treated plants. The data in Table 2 demonstrated that/ spike length of water deficit at all levels was significantly decreased with increased water deficit level in soil, especially at high water stress levels. The highest values of spike length obtained from wheat plants inoculated with AMF, while the minimum spike length recorded from non-mycorrhizal plants grown at high water deficit treatment soil. These results showed a general trend of an increase in grain per spike with inoculation of treated plants (Table 2). Seed index weight of 100 grains ( $\mathrm{g}$ ) was recorded and the data revealed that grain index was significantly increased in mycorrhizal wheat inoculated plant than those uninoculated wheat plants. The root colonization rate was affected by substrate, inoculation, and the interaction of the substrate with drought stress or inoculation. In general, different levels of drought stimulated development the frequencies of root colonization $(\mathrm{F} \%)$, the intensity of root cortex colonization (M\%), and arbuscular development (A\%) by Acaulospora capsicula, Glomus aggregatum, and Glomus geosporum at different growth stages in wheat plants as shown in Table 3.

Table 3. Mycorrhizal colonization of wheat plants under different levels (D0, D1, D2, and D3) of drought stress

\begin{tabular}{c|c|cccc}
\hline \multirow{2}{*}{ Growth stages } & Mycorrhizal colonization (\%) & \multicolumn{4}{|c}{ Drought levels } \\
\cline { 2 - 6 } Vegetative & F \% & 48.0 & 52.0 & 43.0 & 36.0 \\
& M \% & 21.3 & 20.0 & 17.0 & 15.3 \\
& A \% & 16.7 & 13.0 & 8.0 & 5.3 \\
\hline \multirow{2}{*}{ Flowering } & F \% & 63.0 & 69.0 & 60.0 & 49.0 \\
& M \% & 54.0 & 58.0 & 49.0 & 43.3 \\
& A \% & 36.3 & 42.3 & 35.6 & 29.0 \\
\hline \multirow{2}{*}{ Maturity } & F \% & 83.3 & 85.0 & 75.0 & 62.0 \\
& M \% & 57.2 & 62.0 & 53.0 & 55.0 \\
& A \% & 53.3 & 58.0 & 44.3 & 48.0 \\
\hline
\end{tabular}

*F\%: Frequency of mycorrhizal root segments, M\%: the intensity of mycorrhizal colonization in the root, A\%: Arbuscule frequency in roots

The microscopic assessment confirmed that plants of non-inoculation treatment were not colonized by AMF. As is evident from Table 3, at the vegetative stage, the highest value of frequency of mycorrhizal root segments recorded under a low level of drought. At the flowering stage, mycorrhizal colonization increased as compared with those of vegetative stage, and $\mathrm{F} \%, \mathrm{M} \%$, and $\mathrm{A} \%$ recorded a maximum value under a low level of drought.

It was observed that the highest mycorrhizal colonization was recorded at the maturity stage (as compared with those of vegetative and flowering stage). Frequency percentage of mycorrhizae in roots reduced at the vegetative stage by about $4 \%$, whereas increased by about $8 \%$ and $5 \%$ in flowering stage and maturity, respectively at low drought level (D1). The moderate (D2) and high (D3) drought levels obviously reduced the percentage of arbuscular mycorrhizae frequency in roots at the different 
stages of plant growth. The mycorrhizae in roots of wheat plants consisted of arbuscules, vesicles, as well as intra-and extraradical hyphae. The arbuscules and vesicles were patchily distributed along the roots examined. The intraradical hyphae were evenly distributed and frequently formed coils.

The phosphorus content of wheat plant shoots inoculated with AMF grown at different levels of the drought was represented in Fig. 1A. The data revealed that $\mathrm{P}$ uptake was significantly reduced by drought treatments. The $\mathrm{P}$ contents of wheat shoots were used as indicators of mycorrhizal activity in the soil. Mycorrhizal inoculation of the wheat plant significantly raised the P uptake especially at low drought level (D1) and shoots of mycorrhizal wheat plants had significantly higher concentrations of $\mathrm{P}$ than those of nonmycorrhizal wheat plants.

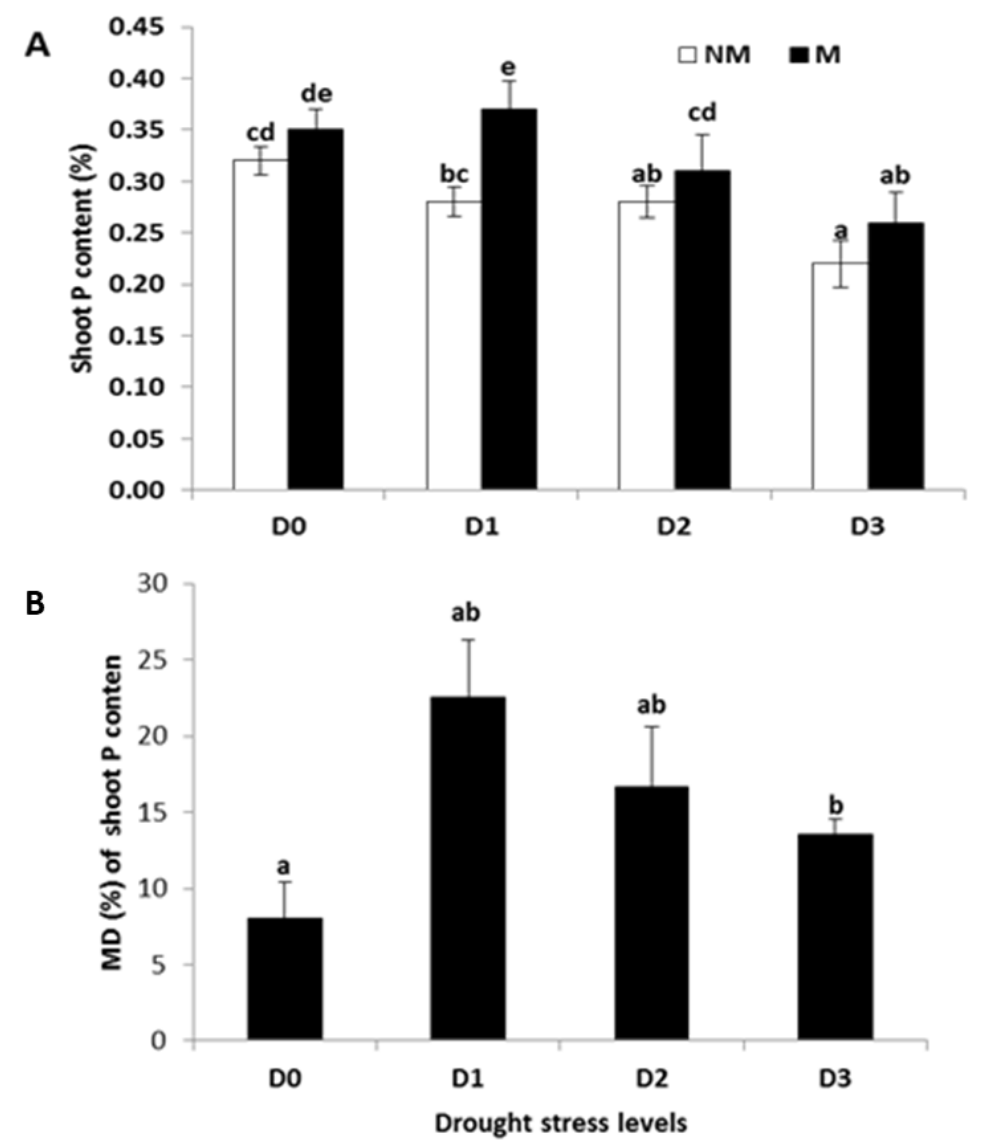

Figure 1. Effect of different levels (D0, D1, D2, and D3) of drought on/ (A) wheat shoot phosphorus content (\%); (B) Mycorrhizal dependency of $P$ wheat shoot content (\%). Means in each column followed by the same letter are not significantly different $(P<0.05)$ as determined by Duncan's test. Values are the means of three replications

\section{Photosynthetic pigments}

The content of the photosynthetic pigments (chlorophyll a, chlorophyll $b$ and carotenoids) of mycorrhizal and non-mycorrhizal in wheat plant leaves are presented as $\mathrm{mg} \mathrm{g}^{-1}$ leaf fresh weight in Figure 2. The current study shows that photosynthetic pigment fractions are significantly affected water deficit and mycorrhizal inoculation as indicated by significant two-way interaction based on ANOVA. In general, with all 
treatments, the content of photosynthetic pigment fractions was decreased as the level of drought increased in the soil pot experiment.

However, the contents of photosynthetic pigments of mycorrhizal wheat plant leaves were significantly $(p<0.05)$ greater than those of non-mycorrhizal ones. In nonmycorrhizal plants a significant reduction in total pigments was recorded at high water deficit (D3).

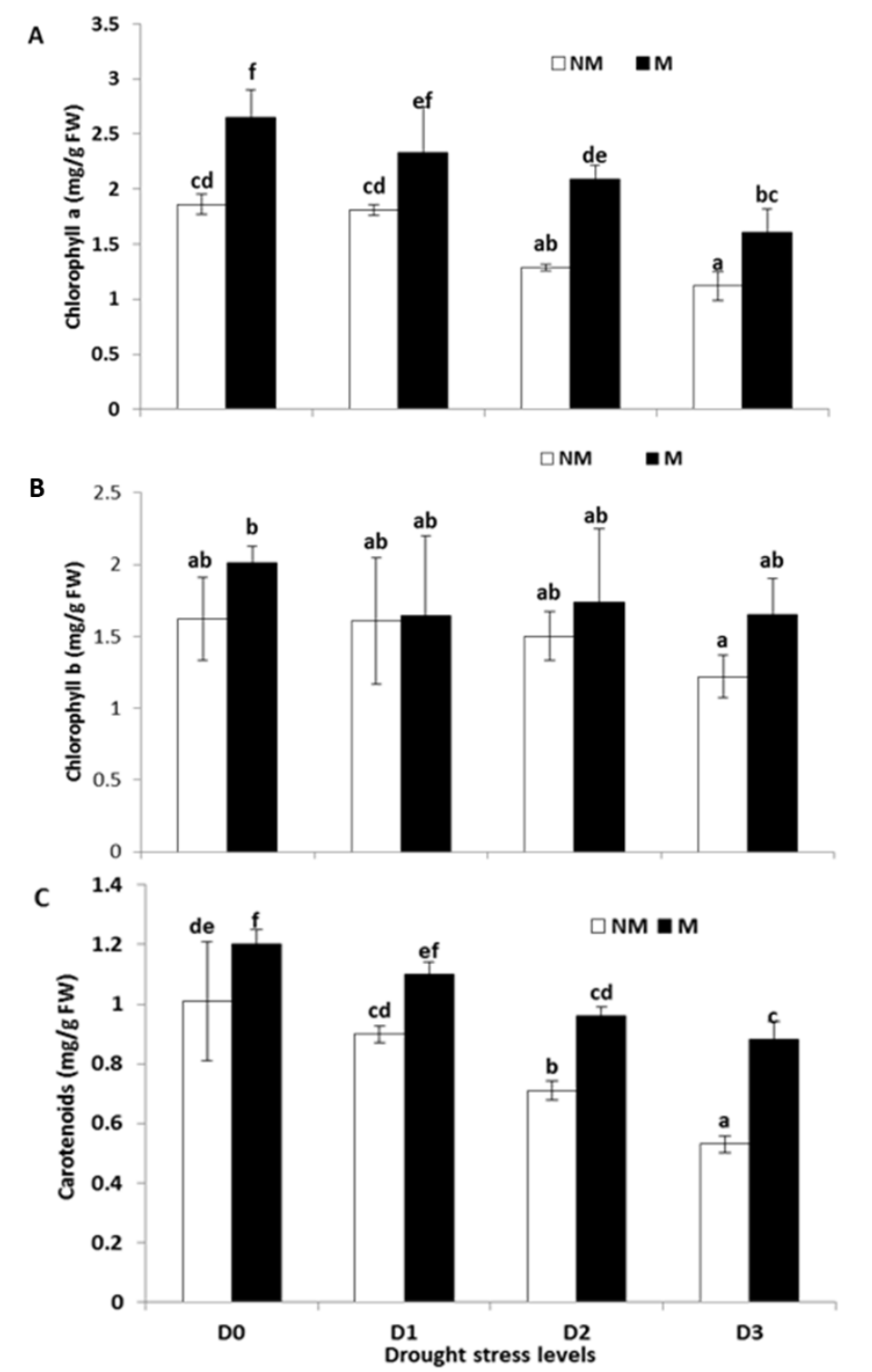

Figure 2. Chlorophyll a (A); chlorophyll $b(B)$; and carotenoids $(C)$ contents in leaves of wheat plants inoculated with mycorrhizal fungi grown under different levels $(D 0, D 1, D 2$, and D3) of drought stress. Means in each column followed by the same letter are not significantly different $(P<0.05)$ as determined by Duncan's test. Values are the means of three replications

Analysis of variance of chlorophyll contents showed that mycorrhizal colonization significantly improved chlorophyll concentrations. Also, the interaction of drought and mycorrhizal inoculation exhibited a stimulatory effect on the different types of photosynthetic pigments (Fig. 2). 


\section{Discussion}

In the present study, drought decreased the fresh and dry weights of wheat plants which are recorded by many studies (Auge, 2001; Celebi et al., 2010; Kyriazopouls et al., 2014). Previous reports have indicated that drought stress severely affects plant growth through various mechanisms, such as reduced leaf water potential, reduced rate of cell division, and altered plant water and nutrient relationships (Boomsma and Vyn, 2008; Kilic and Yagbasanlar, 2010; Farooq et al., 2012). The positive effect of AMF on wheat growth under different levels of drought suggested that the application of AMF technology may be a sustainable method for improving plant performance under the adverse conditions (Kyriazopouls et al., 2014; Malik et al., 2017). AM symbiosis drives an increase in the leaf area and coarse root mass and improves the plant-soil water relationship under drought stress, which can affect various physiological processes. The improvement of biomass in mycorrhizal plants may also be due to the enhanced water uptake (Subramanian et al., 2006; Habibzadeh et al., 2013). Our results in Table 2 are in accordance with the current tendency for reduced use of agrochemicals, research is currently aimed at crop yield improvement and at yield sustainability; thus, microbial-based approaches have been proposed to improve crop yield (Covacevich et al., 2007). In this respect, numerous researchers have reported improvement in biomass production and grain yield in the grain of cereals after inoculation with AMF (Tarafdar and Marschner, 1994). The fungal filaments outside the root system can spread and explore soil areas not reachable by plant roots. One centimeter of colonized roots might produce 50 to $150 \mathrm{~cm}$ of extraradical hyphae (Harley, 1989). Through this mechanism, AMF associations may improve crop yield by increasing the capacity of plants to obtain nutrients that are relatively immobile in the soil such as phosphorus (P).

Our results in accordance with most studies which indicated that drought stress decreased the colonization rates (Kohler et al., 2009; El-Mesbahi et al., 2012) and may be due to the adaptation of AMF isolates to different substrates and different behaviors of plants under drought stress (Gholamhoseini et al., 2013). The decrease of root colonization by drought stress is due to reducing spore germination and plant photosynthetic capacity (Wu et al., 2013; Xiao-Qing et al., 2017). Michalis et al. (2013) concluded that soil moisture can have various effects on AMF spore germination and thus root colonization. Moreover, drought modifies various features of the root system which, in turn, may influence the degree of colonization and the frequency of different AM fungal structures (Fusconi and Berta, 2012). Some results opposite to our studies and showed that mycorrhizal colonization increased with increasing intensity of drought stress (Zhao et al., 2015). They concluded that under drought stress, watering caused lighter compaction, better pore structure and soil aeration, which benefits the development of mycorrhizae.

Drought stress may reduce nutrient mineralization by lowering nutrient availability (Heidari and Karami, 2014). Mycorrhizal symbiosis may improve plant nutrition, which is generally regarded as an important drought tolerance mechanism (Smith and Read, 2008; Li et al., 2012). Hijikata et al. (2010) noticed that the activity of high-affinity P transporters on the plasma membrane of extraradical hyphae is most likely directly involved in enhanced drought tolerance in plants. In the present study, the $\mathrm{P}$ contents in mycorrhizal plants were consistently higher than those in non-mycorrhizal plants, regardless of the intensity of drought stress. The increase in $\mathrm{P}$ concentrations of mycorrhizal plants may provide more RNA to meet the protein synthesis needs, resulting in a higher plant growth rate (Matzek and Vitousek, 2009). Under drought conditions, the RNA-directed synthesis of some protein or enzymes may be of physiological importance in helping the plants withstand drought stress (Fan and Liu, 2011). 
The results obtained showed that wheat plants under drought stress were strongly mycorrhizal dependent (Fig. 1B). The lowest mycorrhizal dependency recorded at the control drought level. SchiiBler et al. (2001) stated that arbuscular mycorrhiza is formed in about $80 \%$ of land plants with soil fungi belonging to Glomeromycota. Arbuscular mycorrhizal plants can take up more soil nutrients especially phosphate $(\mathrm{P})$, micronutrients such as copper and zinc, than non-mycorrhizal plants (Smith and Read, 1997). They concluded that the growth of a host plant can be improved by mycorrhizal colonization provided that soil available $\mathrm{P}$ is a limiting factor for plant growth. The degree of growth improvement is affected by factors such as host plant species, fungal species, and soil conditions.

Analysis of variance of chlorophyll contents (Fig. 2) revealed that mycorrhizal colonization significantly improved chlorophyll concentrations and the interaction of drought and mycorrhizal inoculation exhibited a stimulatory effect on the different types of photosynthetic pigments. Chlorophyll status is a key index for evaluating plant photosynthetic efficiency and environmental stress. Augé (2001), Gemma et al. (1997) and Azooz and Youssef (2010) are in agreement with the results of other proved the differences of chlorophyll $a$, chlorophyll $b$ and chlorophyll $a+b$ concentrations were significant between AM and non-AM maize plants under drought stress conditions (Zafari et al., 2017). They suggest that drought stress interferes less with chlorophyll synthesis and/or more with chlorophyll breakdown (Evelin et al., 2009) or protects pigments against (Kyriazopouls et al., 2014) oxidative damage generated by drought (Shinde and Thakur, 2015). Drought stress caused a great decline in the chlorophyll $a$, chlorophyll $b$ and the total chlorophylls content in many plant varieties investigated by some authors in nonmycorrhizal than mycorrhizal in plants (Ommen et al., 1999; Manivannan et al., 2007; Evelin et al., 2009). Also, unchanged chlorophyll level during drought stress has been reported in other species, depending on the duration and severity of drought (Kpyoarissis et al., 1995). The decrease in chlorophyll under drought stress may result in chloroplast damage caused by active oxygen species (Herbinger et al., 2002). Consequently, the rate of photosynthesis decreased (Kawamitsu et al., 2000) due to lower stomatal conductance in order to conserve water and the resistance of the stomata to $\mathrm{CO}_{2}$ entry probably is the main factor limiting photosynthesis under drought, resulting in less assimilate production for growth and yield of plants.

\section{Conclusion}

The mycorrhizal root colonization rate was significantly affected by drought stress levels or the stages of plant growth of wheat plants. Also, it can be concluded that the AMF enhances the absorption of phosphorus and other nutritional elements and then improves the nutritional status of wheat plants during drought stress which resulted in an increase in chlorophyll contents than control plants. In spite of better performance of inoculation with mycorrhizae, there are still certain aspects that need critical consideration. One important aspect is the evaluation of this approach under natural field conditions. Most of the previous studies were conducted under controlled conditions, and the response of these organisms observed under such conditions may vary significantly in view of the variable ecology of these microorganisms in the natural environment. Additionally, the researches also have to face other harsh conditions like the toxicity of heavy metals and pathogen attacks. Therefore, the role of these microorganisms for providing relief from other stresses. 
Acknowledgment. The authors extend their gratitude to the Deanship of Scientific Research (DSR), King Faisal University, Saudi Arabia, for providing a fund of the current work (DSR, project No. 150161).

\section{REFERENCES}

[1] Abd-Alla, M. H., El-Enany, A. E., Bagy, M. K., Bashandy, S. R. (2014a): Alleviating the inhibitory effect of salinity stress on nod gene expression in Rhizobium tibeticum fenugreek (Trigonella foenum graecum) symbiosis by isoflavonoids treatment. - Journal of Plant Interaction 9: 275-284.

[2] Abd-Alla, M. H., El-Enany, A. E., Nafady, N. A., Khalaf, D. M., Morsy, F. M. (2014b): Synergistic interaction of Rhizobium leguminosarum bv. viciae and arbuscular mycorrhizal fungi as a plant growth-promoting biofertilizers for faba bean (Vicia faba L.) in alkaline soil. - Microbiological Research 169: 49-58.

[3] Abdel Latef, A. A. H., Chaoxing, H. (2014): Does Inoculation with Glomus mosseae Improve Salt Tolerance in Pepper Plants? - Journal of Plant Growth Regulation 33: 644653.

[4] Al-Karaki, G. N., Clark, R. B. (1998): Growth, mineral acquisition, and water use by mycorrhizal wheat grown under water stress. - Journal of Plant Nutrition 21: 263-276.

[5] Aroca, R., Porcel, R., Ruiz-Lozano, J. M. (2007): How does arbuscular mycorrhizal symbiosis regulate root hydraulic properties and plasma membrane aquaporins in Phaseolus vulgaris under drought, cold and salinity stresses? - New Phytologist 173: 808-816.

[6] Asrar, A. A., Abdel-Fattah, G. M., Elhindi, K. M. (2012): Improving growth, flower yield, and water relations of snapdragon (Antirhinum majus L.) plants grown under wellwatered and water stress conditions using arbuscular mycorrhizal fungi. Photosynthetica 50: 305-316.

[7] Augé, R. M. (2001): Water relations, drought ,and vesicular-arbuscular mycorrhizal symbiosis. - Mycorrhiza 11: 3-42.

[8] Augé, R. M., Toler, H. D., Moore, J. L., Cho, K., Saxton, A. M. (2007): Comparing contributions of soil versus root colonization to variations in stomatal behavior and soil drying in mycorrhizal Sorghum bicolor and Cucurbita. - Journal of Plant Physiology 164: 1289-1299.

[9] Azooz, M. M., Youssef, M. M. (2010): Evaluation of heat shock and salicylic acid treatments as inducers of drought stress tolerance in hassawi wheat. - American Journal of Plant Physiology 5: 56-70.

[10] Barea, J. M., Werner, D., Azcón-Guilar, C., Azcón, R. (2005): Interactions of arbuscular mycorrhiza and nitrogen-fixing symbiosis in sustainable agriculture. - In: Werner, D., Newton, W. E. (eds.) Nitrogen Fixation in Agriculture, Forestry, Ecology, and the Environment. Springer Netherlands pp: 199-222.

[11] Bárzana, G., Aroca, R., Paz, J. A., Chaumont, F., Martinez-Ballest, M. C., Carvajal, M. I. (2012): Arbuscular mycorhhizal symbiosis increases relative apoplastic water flow in roots of the host plant under both well-watered and drought stress conditions. - Annals of Botany 109: 1009-1017.

[12] Bohnert, H. J., Nelson, D. E., Jensen, R. G. (1995): Adaptations to environmental stresses. - The Plant Cell 7: 1099-1111.

[13] Bompadre, M. J., Silvani, V. A., Bidondo, L. F., Ríos de Molina, M. D. C., Roxana, P. C., Pardo, A., Galicia, M. G. (2014): Arbuscular mycorrhizal fungi alleviate oxidative stress in pomegranate plants growing under different irrigation conditions. - Botany 92: 187193.

[14] Boomsma, C. R., Vyn, T. J. (2008): Maize drought tolerance: potential improvements through arbuscular mycorrhizal symbiosis? - Field Crops Research 108: 14-31. 
[15] Brundrett, M. C., Piche, Y., Peterson, R. L. (1984): A new method for observing the morphology of vesicular-arbuscular mycorrhizae. - Canadian Journal of Botany 62: 2128-2134.

[16] Celebi, S. Z., Demir, S., Celebi, R., Durak, E. D., Yilmaz, I. H. (2010): The effect of arbuscular mycorrhizal fungi (AMF) applications on the silage maize (Zea mays L.) yield in different irrigation regimes. - European Journal of Soil Biology 46: 302-305.

[17] Covacevich, F., Echeverria, H. E., Aguirrezabal, L. (2007): Soil available phosphorus status determines indigenous mycorrhizal colonization into a field and glasshouse-grown spring wheat in Argentina. - Applied Soil Ecology 35: 1-9.

[18] El-Enany, A. E., Al-Anazi, A. D., Nahla, D., Al-Taisan, W. A. (2013): Role of antioxidant enzymes in amelioration of water deficit and waterlogging stresses on Vigna Sinensis plants. - Journal of Biology and Earth Sciences 1: 144-153.

[19] El-Enany, A. E., Morsy, F., Nahla, D. (2014): Impact of water stress on growth criteria and alcohol dehydrogenase activity of three legume plants. - Minia Science Bulletin 25: 29-51.

[20] El-Mesbahi, M. N., Azcón, R., Ruiz-Lozano, J. M., Aroca, R. (2012): Plant potassium content modifies the effects of arbuscular mycorrhizal symbiosis on root hydraulic properties in maize plants. - Mycorrhiza 22: 555-564.

[21] Evelin, H., Kapoor, R., Giri, B. (2009): Arbuscular mycorrhizal fungi in alleviation of salt stress: a review. - Annals of Botany 104: 1263-1280.

[22] Fan, Q. J., Liu, J. H. (2011): Colonization with arbuscular mycorrhizal fungus affects growth: drought tolerance and expression of stress-responsive genes in Poncirus trifoliate. - Acta Physiologae Plantarum 33: 1533-1542.

[23] Farooq, M., Hussain, M., Wahid, A., Siddique, K. H. M. (2012): Drought stress in plants - an overview. - In: Aroca, R. (ed.) Plant Responses to drought Stress: from morphological to molecular features. Springer, Berlin Heidelberg, pp. 1-33.

[24] Fusconi, A., Berta, G. (2012): Environmental stress and role of arbuscular mycorrhizal symbiosis. - In: Ahmad, P., Prasad, M. N. V. (eds.) Abiotic Stress Responses in Plants: Metabolism, Productivity and Sustainability. Springer, New York, pp. 197-214.

[25] Gemma, J. N., Koske, R. E., Roberts, E. M., Jackson, N., De Antonis, K. (1997): Mycorrhizal fungi improve drought resistance in creeping bentgrass. - Journal of Turfgrass Science 73: 15-29.

[26] Gholamhoseini, M., Ghalavand, A., Dolatabadian, A., Jamshidi, E., Khodaei-Joghan, A. (2013): Effects of arbuscular mycorrhizal inoculation on growth yield, nutrient uptake and irrigation water productivity of sunflowers grown under drought stress. - Agricultural Water Management 117: 106-114.

[27] Habibzadeh, Y., Pirzad, A., Zardashti, M. R., Jalilian, J., Eini, O. (2013): Effects of Arbuscular Mycorrhizal Fungi on Seed and Protein Yield under Water-Deficit Stress in Mung Bean. - Agronomy Journal 105: 79-84.

[28] Harley, J. L. (1989): The significance of mycorrhizal. - Mycological Research 92: 129139.

[29] Heidari, M., Karami, V. (2014): Effects of different mycorrhiza species on grain yield, nutrient uptake and oil content of sunflower under water stress. - Journal of the Saudi society of agricultural sciences 13: 9-13.

[30] Herbinger, K., Tausz, M., Wonisch, A., Soja, G., Sorger, A., Grill, D. (2002): Complex interactive effects of drought and ozone stress on the antioxidant defense systems of two wheat cultivars. - Plant Physiology and Biochemistry 40: 691-696.

[31] Hijikata, N., Murase, M., Tani, C., Ohtomo, R., Osaki, M., Ezawa, T. (2010): Polyphosphate has a central role in the rapid and massive accumulation of phosphorus in extraradical mycelium of an arbuscular mycorrhizal fungus. - New Phytologist 186: 285289. 
[32] Kannenberg, S. A., Phillips, R. P. (2017): Soil microbial communities buffer physiological responses to drought stress in three hardwood species. - Oecologia 183: 631-641.

[33] Kawamitsu, Y., Driscoll, T., Boyer, J. S. (2000): Photosynthesis during desiccation in an Intertidal Alga and a Land Plant. - Plant and Cell Physiology 41(3): 344-353.

[34] Khalvati, M., Bartha, B., Dupigny, A., Schröder, P. (2010): Arbuscular mycorrhizal association is beneficial for growth and detoxification of xenobiotics of barley under drought stress. - Journal of Soils and Sediments 10: 54-64.

[35] Kilic, H., Yagbasanlar, T. (2010): The Effect of Drought Stress on Grain Yield, Yield Components and some Quality Traits of Durum Wheat (Triticum turgidum ssp. durum) Cultivars. - Notulae Botanicae Horti Agrobotanici Cluj-Napoca 38: 164-170.

[36] Kohler, J., Caravaca, F., del Mar, A. M., Roldán, A. (2009): Elevated $\mathrm{CO}_{2}$ increases the effect of an arbuscular mycorrhizal fungus and a plant-growth-promoting rhizobacterium on structural stability of a semiarid agricultural soil under drought conditions. - Soil Biology and Biochemistry 41: 1710-1716.

[37] Kpyoarissis, A., Petropoulou, Y., Manetas, Y. (1995): Summer survival of leaves in a soft-leaved shrub (Phlomis fruticosa L., Labiatae) under Mediterranean field conditions:avoidance of photoinhibitory damage through decreased chlorophyll contents. - Journal of Experimental Botany 46: 1825-1831.

[38] Kyriazopouls, A. P., Orfanoudakis, M., Abraham, E. M., Parissi, Z. M., Serafidou, N. (2014): Effects of Arbuscular Mycorrhiza Fungi on Growth Characteristics of Dactylis glomerata L. under Drought Stress Conditions. - Notulae Botanicae Horti Agrobotanici Cluj-Napoca 42: 132-137.

[39] Lazcano, C. F. B., Barrios-Masias, F. H., Jackson, L. E. (2014): Arbuscular mycorrhizal effects on plant water relations and soil greenhouse gas emissions under changing moisture regimes. - Soil Biology and Biochemistry 74: 184-192.

[40] Li, Y., Cheng, Y. L., Li, M., Lin, X. G., Liu, R. J. (2012): Effects of arbuscular mycorrhizal fungal communities on soil quality and the growth of cucumber seedlings in a greenhouse soil continuously planting cucumber. - Pedosphere 22: 79-87.

[41] Lichtenthaler, H. K. (1987): Chlorophylls and carotenoids: Pigments of photosynthetic biomembranes. - Methods in Enzymology 148: 350-382.

[42] Malik, N. S. A., Alberto, N., McKeever, L. C. (2017): Mycorrhizal Inoculation Increases Growth and Induces Changes in Specific Polyphenol Levels in Olive Saplings. - Journal of Agricultural Science 9(2): doi:10.5539/jas.v9n2p1.

[43] Manivannan, P., Abdul Jaleel, C., Sankar, B., Kishorekumar, A., Somasundaram, R., Lakshmanan, G. M. A., Panneerselvam, R. (2007): Growth, biochemical modifications and proline metabolism in Helianthus annuus L. as induced by drought stress. - Colloids and Surfaces B: Biointerfaces 59: 141-149.

[44] Matzek, V., Vitousek, P. M. (2009): N:P stoichiometry and protein:RNA ratios in vascular plants:an evaluation of the growth-rate hypothesis. - Ecology Letters 12: 765771.

[45] Michalis, O., Ioannides, I. M., Ehaliotis, C. (2013): Mycorrhizal inoculation affects arbuscular mycorrhizal diversity in watermelon roots but leads to improved colonization and plant response under water stress only. - App Soil Ecol 63: 112-119.

[46] Olsen, S. R., Sommers, L. E. (1982): Phosphorus. - In: Page, A. L., Miller, R. H., Keeney, D. R. (eds.) Methods of soil analysis, part 2. Chemical and Microbiological Properties. ASA, SSSA, Madison, Wis, pp 403-430.

[47] Ommen, O. E., Donnelly, A., Vanhoutvin, S., van Oijen, M., Manderscheid, R. (1999): Chlorophyll content of spring wheat flag leaves grown under elevated $\mathrm{CO}_{2}$ concentrations and other environmental stresses within the ESPACE-wheat project. - European Journal of Agronomy 10: 197-203. 
[48] Patale, S. W., Shinde, B. P. (2014): Effect of water and salt stress on Bt-Cotton inoculated with AM fungi. - Indian Journal of Research Studies in Pure and Applied Science 2: 50-56.

[49] Plenchette, C., Fortin, J. A., Furlan, V. (1983): Growth response of several plant species to mycorrhiza in soil of moderate P fertility. I. mycorrhizal dependency under field conditions. - Plant and Soil 70: 199-209.

[50] Quiroga, G., Erice, G., Aroca, R., Chaumont, F., Ruiz-Lozano, J. M. (2017): Enhanced Drought Stress Tolerance by the Arbuscular Mycorrhizal Symbiosis in a DroughtSensitive Maize Cultivar Is Related to a Broader and Differential Regulation of Host Plant Aquaporins than in a Drought-Tolerant Cultivar. - Frontiers in Plant Science 8: doi.org/10.3389/fpls.2017.01056.

[51] Rivera-Becerril, F., van Tuinen, D., Martin-Laurent, F., Metwally, A., Dietz, K-J., Gianinazzi, S., Gianinazzi-Pearson, V. (2005): Molecular changes in Pisum sativum L. roots during arbuscular mycorrhiza buffering of cadmium stress. - Mycorrhiza 16: 51-60.

[52] Ruíz-Lozano, J. M. (2003): Arbuscular mycorrhhizal symbiosis and alleviation of osmotic stress. New perspectives for molecular studies. - Mycorrhiza 13: 309-317.

[53] Schueßler, A., Schwarzott, D., Walker, C. (2001): A new fungal phylum, the Glomeromycota: phylogeny and evolution. - Mycological Research 105: 1413-1421.

[54] Schueßler, A., Walker, C. (2010): The Glomeromycota: a species list with new families and genera. - Edinburgh \& Kew, UK: The Royal Botanic Garden; Munich, Germany: Botanische Staatssammlung Munich; Oregon, USA: Oregon State University. URL:http://www.amf-phylogeny.com. ISBN-13:978- 1466388048; ISBN10:1466388048.

[55] Shinde, B. P., Thakur, J. (2015): Influence of Arbuscular mycorrhizal fungi on chlorophyll, proteins, proline and total carbohydrates content of the pea plant under water stress condition. - International Journal of Current Microbiology and Applied Sciences 4: 809-821.

[56] Shinde, B. P., Singh, N. (2017): Effect of Arbuscular Mycorrhizal Fungi on Growth Parameters of Sweet Corn under $\mathrm{NaCl}$ Salinity. - International Journal of Current Microbiology and Applied Sciences 6: 1317-1325.

[57] Smith, S. E., Read, D. J. (1997): Mycorrhizal symbiosis. - $2^{\text {nd }}$ ed. Academic Press, London.

[58] Smith, S. E., Read, D. J. (2008): Mineral nutrition, toxic element accumulation and water relations of arbuscular mycorrhizal plants. - In: Smith, S. E., Read, D. J. (eds.) Mycorrhizal Symbiosis. $3^{\text {rd }}$ ed. pp. 145-18. Academic Press, London.

[59] Subramanian, K. S., Santhanakrishnan, P., Balasubramanian, P. (2006): Responses of field grown tomato plants to arbuscular mycorrhizal fungal colonization under varying intensities of drought stress. - Scientia Horticulturae 107: 245-253.

[60] Tarafdar, J. C., Marschner, H. (1994): Efficiency of VAM hyphae in utilization of organic phosphorus by wheat plants. - Soil Science and Plant Nutrition 40: 593-600.

[61] Trouvelot, A., Kough, J., Gianinazzi-Pearson, V. (1986): Evaluation of VA infection levels in root systems. - In: Gianinazzi-Pearson, V., Gianinazzi, S. (eds.) Research for estimation methods having a functional significance, Physiological and Genetical Aspects of Mycorrhizae. INRA Press, Paris, France, pp. 217-221.

[62] Wu, Q. S., Srivastava, A. K., Zou, Y. N. (2013): AMF-induced tolerance to drought stress in citrus: A review. - Scientia Horticulturae 164: 77-87.

[63] Xiao-Qing, T., Li, H. E., Ying-Ning, Z. (2017): Alleviation of Drought Stress in White Clover after Inoculation with Arbuscular Mycorrhizal Fungi. - Notulae Botanicae Horti Agrobotanici Cluj-Napoca 45: 220-224.

[64] Zafari, M., Ebadi, A., Godehkahriz, S. J. (2017): Effect of seed Inoculation on Alfalfa Tolerance to water deficit stress. - Notulae Botanicae Horti Agrobotanici Cluj-Napoca 45: 82-88. 
[65] Zhao, R., Guo, W., Bi, N., Guo, J., Wang, L. J., Zhao, J., Zhang, J. (2015): Arbuscular mycorrhizal fungi affect the growth, nutrient uptake and water status of maize (Zea mays L.) grown in two types of coal mine spoils under drought stress. - Applied Soil Ecology 88: 41-49.

[66] Zhu, X. C., Song, F. B., Liu, S. Q., Liu, T. D., Zhou, X. (2012): Arbuscular mycorrhizae improve photosynthesis and water status of Zea mays L. under drought stress. - Plant, Soil and Environment 58: 186-191. 